\title{
CORRELATION BETWEEN URINARY BISPHENOL A, SERUM 25 OH VITAMIN D LEVELS AND PRETERM BIRTH IN EGYPTIAN PREGNANT WOMEN
}

\author{
BY
}

\author{
Sahar A. El-Dakroory ${ }^{1}$, Reem K. Abo-Elmaaty ${ }^{1}$, Sara A. Mohamed ${ }^{2}$,Adel M. El-Mansory' ${ }^{1}$ and \\ Nermin M. Emam ${ }^{1}$
}

${ }^{I}$ Forensic Medicine and Clinical Toxicology Department, Faculty of Medicine, Mansoura University, Egypt. ${ }^{2}$ Obstetrics and Gynecology Department, Faculty of Medicine, Mansoura University, Egypt.

\begin{abstract}
Introduction: Preterm birth (PTB) is a worldwide cause of infant mortality and morbidity. Prenatal exposure to endocrine disrupting chemicals (EDCs) especially bisphenol A (BPA) is questioned as a potential risk factor for PTB. Lower gestational vitamin D levels are associated with various maternal and fetal complications. Aim of the Work: This study aimed to evaluate the gestational exposure to BPA and the potential association between urinary BPA and serum vitamin D levels in a sample of Egyptian women having spontaneous PTB. Subjects and Methods: This study was conducted on 106 reproductive aged females divided into Group I with full term delivery (37-42 weeks gestational age) as "control group" and Group II with spontaneous preterm contractions (24 $<37$ weeks gestational age) that ended with preterm delivery as "PTB group". Results: The median level of urinary uncorrected and specific gravity (SG)-corrected BPA was found to be higher in PTB group with high statistically significant difference between both studied groups $(\mathrm{P}<0.001)$. Vitamin D deficiency $(\leq 20 \mathrm{ng} / \mathrm{ml})$ was detected in $35.8 \%$ of PTB cases with a statistically significant difference $(\mathrm{P}=0.001)$ among the studied groups. There was statistically significant strong negative correlation $(\mathrm{P}<0.001)$ between serum vitamin $\mathrm{D}$ and both urinary uncorrected and SGcorrected BPA among the PTB group. Conclusions: high Urinary BPA and low vitamin D levels represent possible predictive environmental risk factors for PTB.

Keywords: Bisphenol A, Vitamin D, Preterm birth.
\end{abstract}

Corresponding author: Dr. Nermin M. Emam

Email: nermin_toxo1981@hotmail.com

\section{INTRODUCTION}

$\mathbf{T}$ he widespread use of industrial chemicals and their risk of adverse pregnancy sequences had been appreciated over years. Preterm birth (PTB) refers to "the delivery before the 37 th week of pregnancy" and the most common cause of worldwide infantile mortality. The World Health Organization reported that about 15 million neonates are born preterm with about 1 million deaths occurring during infancy (Baer et al., 2019).

There is increasing conviction that PTB is a condition with a variety of potentially independent causes, rather than a single disorder. There are several reported risk factors of PTB such as extremes of maternal age during pregnancy, unhealthy lifestyle, malnutrition and environmental pollutants exposure (Mustieles et al., 2018).

Bisphenol A (BPA) levels have been the most reliable measure of phenolic estrogens in the environment. It is a synthetic chemical widely used in plastic industry and many consumer products including thermal papers, canned food, cosmetics in addition to medical supplies. When these products are repeatedly exposed to high temperatures, ultraviolet rays, acidic or basic media, BPA leach out and leads to due to its pervasiveness in the ecosystem. As a result, humans are subjected to BPA on a regular basis (Johnson et al., 2016).

Vitamin D deficiency is widespread throughout the world, particularly during pregnancy. While ultraviolet radiation from sunlight is the most common source of vitamin $\mathrm{D}$ in the human body, it can also be obtained via diet. Vitamin $D$ is biologically inactive before it is transferred to the liver and then converted to 25hydroxyvitamin D [25(OH)D], which represent vitamin D nutritional status of the body (Chang and Lee, 2019). 
Despite the fact that vitamin $\mathrm{D}$ is important in the skeletal health development and maintenance, the presence of its receptor and metabolic enzymes in reproductive tissues and organs points out to the possible regulatory role of it in female reproductive system and pregnancy (Tehrani and BehboudiGandevani, 2017).

Therefore, maintaining vitamin $\mathrm{D}$ equilibrium during pregnancy is crucial for placentation, adequate healthy pregnancy along with normal fetal growth and development. Preeclampsia, spontaneous PTB and restricted fetal growth have all been related to low vitamin D levels during pregnancy, according to several researchers (Murthi et al., 2016).

\section{Aim of the Work:}

The aim of this study was to evaluate gestational BPA exposure and the potential association between urinary BPA and serum vitamin D levels in a sample of Egyptian women having spontaneous PTB.

\section{Subjects and Methods:}

\section{Study Design:}

This case control study was conducted on 106 reproductive aged females in the period from 1st January till the end of June, who had regular uterine contractions with cervical effacement and dilatation that led into delivery. The present study was carried out in collaboration with Gynecology and Obstetrics department, Faculty of Medicine, Mansoura University. The study was approved by the Institutional Review Board (IRB), Faculty of Medicine, Mansoura University (MD/17.12.39). An informed written consent was obtained from all patients before enrollment in the research.

\section{Subjects:}

Patients in the present study were grouped into:

1. Group I (Control group): 53 healthy women came to Gynecology and Obstetrics department with normal labor pain that end with full term delivery (37-42 weeks gestational age).
2. Group II (PTB group): 53 healthy women came to Gynecology and Obstetrics department with spontaneous preterm contractions and or preterm premature rupture of membranes ( 24 to $<37$ weeks gestational age) that end with preterm delivery.

\section{- Inclusion Criteria:}

Pregnant women aged from 18 to 40 years at delivery time and had menstrual cycles between 21-35 days without any injectable hormonal contraceptives in the past year were included in the study.

\section{- Exclusion Criteria:}

Subjects with fetal anomalies and chromosomal disorders, multiple gestations (triplets or greater), elective delivery before 37 weeks, preeclampsia, placenta previa, gestational diabetes, endocrinal disorders and surgical complications of pregnancy were excluded. In addition, chronic infections such as "Tuberculosis and sexually transmitted infections", malabsorption, history of previous surgical complications of pregnancy, maternal anemia, inflammatory diseases, fibroid, ovarian cyst, smoking, drug abuse, alcohol consumption and previous treatment for malignancy were also excluded.

Methods:

1. Sociodemographic data and obstetric history collection:

The female's social history including her age and residence in addition to her obstetric history including her gestational age per weeks and female's parity status were collected confidentially.

2. Clinical assessment:

Clinical data were collected from subjects' interview after female's stabilization following delivery and from medical records. Gestational age was stationed on the date of last menstrual period and verified also by ultrasound.

3. Urinary BPA level determination:

Five milliliters of morning urine were collected in a sterile "BPA free" polypropylene plastic cup. All urine 
samples were stored in deep freeze at $20^{\circ} \mathrm{C}$ until analysis. Digestion and extraction of urine samples was done according to the method of Liao and Kannan, (2012). Samples were analyzed at Nawah Scientific Research Center using high performance liquid chromatography (HPLC-Waters 2695) with a photo diode array (PDA) detector.

4. Serum vitamin D level estimation:

Five milliliters of maternal blood were collected in EDTA tubes at admission for delivery then were centrifuged at 3500 rpm for 5 minutes to obtain serum and stored at $-20^{\circ} \mathrm{C}$ until analysis. Estimation of vitamin D level was done using "EDITM Total 25-OH Vitamin D Enzyme Immunoassay Kit" according to the manufacturer manual at Mansoura Research Center for Cord Stem Cell, Faculty of Medicine using PR 4100 "Absorbance Microplate Reader" at wavelength $450 \mathrm{~nm}$.

Statistical Analysis:

Data was analyzed using the computer program SPSS (Statistical Package for Social Sciences) version release 16.0 to obtain descriptive statistics including frequency analysis. "One way ANOVA", "Student t-test", Monte Carlo test "Chi-square test", "Kruskal-Wallis" and "Mann-Whitney test" was performed for statistical comparison. Correlation was evaluated using "Spearman correlation test" and "Binary stepwise logistic regression analysis" was used for algorithmic transformation and linear regression analysis. $\mathrm{P}$ value is considered significant at $\leq 0.05$ and highly statistically significant at $<0.001$.

\section{RESULTS}

Sociodemographic data are shown in table (1), the mean age of both control and PTB groups was 28.26 \pm 6.39 and $29.11 \pm 6.78$ years respectively with no statistically significant difference in between ( $\mathrm{P}=0.508)$. Regarding female's parity, the majority of the females in both control and PTB groups (43.4\% and $43.5 \%$ respectively) were para 1 with no statistically significant difference between both groups $(\mathrm{P}=0.111)$.

The studied groups were evaluated for vitamin $\mathrm{D}$ deficiency and insufficiency as shown in table (2). It was found that vitamin $\mathrm{D}$ deficiency $(<20 \mathrm{ng} / \mathrm{ml})$ presented in $1(1.9 \%)$ case in control group and $19(35.8 \%)$ cases in PTB group. On the other hand, vitamin $\mathrm{D}$ insufficiency (20-30 $\mathrm{ng} / \mathrm{ml})$ was in $16(30.2 \%)$ cases in control group and $9(17 \%)$ cases in PTB group with statistically significant difference $(\mathrm{P}=0.001)$ between both the studied groups.

The median level of serum vitamin D, urinary uncorrected and SG-corrected BPA in both control and PTB groups were shown in table (3), the median serum vitamin D level was found to be 32 (1696.4) $\mathrm{ng} / \mathrm{ml}$ in the control group while in the PTB group was $35(9.4-75.5) \mathrm{ng} / \mathrm{ml}$ with no statistically significant difference $(\mathrm{P}=0.945)$ among the studied groups as shown in figure (1). The median levels of urinary uncorrected and SG-corrected BPA were found to be higher in PTB group $(2.56,2.63 \mathrm{ng} / \mathrm{ml}$ respectively) versus control group $(0.26, \quad 0.35 \mathrm{ng} / \mathrm{ml}$ respectively) with high statistically significant difference between both the studied groups $(\mathrm{P}<0.001)$ as shown in figures $(\mathbf{2}, \mathbf{3})$.

Association between demographic data, obstetric history, serum vitamin D level and urinary SG-corrected BPA of the studied PTB cases was shown in table (4), there was no statistically significant association between high urinary SGcorrected BPA levels and the age of the pregnant female $(\mathrm{P}=0.668)$ nor her parity status $(\mathrm{P}=0.405)$. Moreover, there was no statistically significant association between high urinary SG-corrected BPA levels and the median gestational age and preterm degree of the pregnant female $(\mathrm{P}=0.054)$. However, there was a statistically significant association of high urinary SGcorrected BPA levels in cases who lived in urban areas $(\mathrm{P}=0.01)$.

On the other hand, there was a 
statistically significant association between high urinary SG-corrected BPA levels and serum vitamin $\mathrm{D}$ deficiency $(\mathrm{P}=0.003)$. Moreover, the correlation coefficients between uncorrected, SG-corrected BPA and vitamin D of the PTB group were ( $\mathrm{r}=-$ $0.644)$ and ( $\mathrm{r}=0.638)$ respectively with statistically significant negative correlation $(\mathrm{P}<0.001)$ as shown in table (5) and figures $(4,5)$.
The prediction of preterm labor among the studied groups was shown in table (6), there were high statistically significant role of urinary uncorrected and SG-corrected BPA in prediction of preterm labor $(\mathrm{P}<0.001)$, with no statistically significant role of serum vitamin D levels nor the age of the pregnant female at the time of labor or her parity status in prediction of PTB.

Table (1): Demographic characteristics and obstetric history among the studied groups.

Variables
Control group
"Group I"
$\mathrm{n}=(53)$

Age/years

Mean \pm SD
$28.26 \pm 6.39$

$$
\begin{gathered}
\text { PTB group } \\
\text { "Group II" } \\
n=(53)
\end{gathered}
$$

$29.11 \pm 6.78$ test of significance

(P-value)

$$
\mathrm{t}=0.664
$$

$(\mathrm{P}=0.508)$

\section{Residence}

Rural

$32(60.4 \%)$

$34(64.2 \%)$

$\chi^{2}=0.161$

Urban

$21(39.6 \%)$

$19(35.8 \%)$

$(\mathrm{P}=0.689)$

Gestational age/weeks

Mean \pm SD

$38.0 \pm 1.02$

$31.75 \pm 2.43$

$\mathrm{t}=7.41$

$(\mathrm{P}<0.001 * *)$

Parity

$\begin{array}{lccc}\text { Nulli-para } & 13(24.5 \%) & 22(41.5 \%) & \\ 1 & 23(43.4 \%) & 23(43.5 \%) & \text { MC } \\ 2 & 13(24.5 \%) & 8(15.1 \%) & (\mathrm{P}=0.111) \\ 3 & 3(5.7 \%) & 0 & \\ 4 & 1(1.9 \%) & 0 & \end{array}$

PTB: preterm birth, n: number, SD: standard deviation, t: Student t test, MC: Monte Carlo

\begin{tabular}{|c|c|c|c|}
\hline $\begin{array}{l}\text { Serum Vitamin D } \\
(\mathrm{ng} / \mathrm{ml})\end{array}$ & $\begin{array}{c}\text { Control group } \\
\text { "group I" } \\
\text { n=53 }\end{array}$ & $\begin{array}{c}\text { PTB group } \\
\text { "group II" } \\
\text { n=53 }\end{array}$ & $P$ value \\
\hline Deficiency $(<20)$ & $1(1.9 \%)$ & $19(35.8 \%)$ & \\
\hline Insufficiency (20-30) & $16(30.2 \%)$ & $9(17 \%)$ & MC \\
\hline Optimal (>30-70) & $22(41.5 \%)$ & $18(34 \%)$ & $\mathrm{P}=0.001 *$ \\
\hline Overdose $(>70)$ & $14(26.4 \%)$ & $7(13.2 \%)$ & \\
\hline
\end{tabular}
test, $\chi^{2}$ : Chi square test *statistically significant (if $\mathrm{P} \leq 0.05$ ), **highly statistically significant (if $\mathrm{P}<0.001$ ).

Table (2): Interpretation of serum vitamin D levels in all the studied groups.

$\mathrm{n}$ : number, ng/ml: nanogram per millimeter, PTB: preterm birth, MC: Monte Carlo test *statistically significant (if $\mathrm{P} \leq 0.05$ ). 
Table (3): Serum vitamin D, urinary uncorrected and urinary specific gravity-corrected bisphenol A levels among the studied groups.

\begin{tabular}{lccc}
\hline $\begin{array}{l}\text { Variables } \\
(\mathrm{ng} / \mathrm{ml})\end{array}$ & $\begin{array}{c}\text { Control group } \\
\text { "Group I" } \\
\mathrm{n}=(53)\end{array}$ & $\begin{array}{c}\text { PTB group } \\
\text { "Group II" } \\
\mathrm{n}=(53)\end{array}$ & $\begin{array}{c}\text { test of } \\
\text { significance } \\
\text { (P-value })\end{array}$ \\
\hline $\begin{array}{l}\text { Serum Vitamin D } \\
\text { Median (min-max) }\end{array}$ & $32.0(16.0-96.4)$ & $35.0(9.4-75.5)$ & $\begin{array}{l}\mathrm{Z}=0.069 \\
\mathrm{P}=0.945\end{array}$ \\
$\begin{array}{l}\text { Urinary uncorrected BPA } \\
\text { Median (min-max) }\end{array}$ & $0.26(0.0-6.98)$ & $2.56(0.04-15.34)$ & $\begin{array}{c}\mathrm{Z}=6.22 \\
\left(\mathrm{P}<0.001^{* *}\right)\end{array}$ \\
$\begin{array}{l}\text { Urinary SG-Corrected BPA } \\
\text { Median (min-max) }\end{array}$ & $0.35(0.0-5.23)$ & $2.63(0.04-17.62)$ & $\begin{array}{c}\mathrm{Z}=6.21 \\
\left(\mathrm{P}<0.001^{* *}\right)\end{array}$ \\
\hline
\end{tabular}

PTB: preterm birth, $\mathrm{n}$ : number, $\mathrm{ng} / \mathrm{ml}$ : nanogram per millimeter, min: minimum, max: maximum, BPA: Bisphenol A, SG: specific gravity, Z: Z score, MC: Monte Carlo test *statistically significant (if $\mathrm{P} \leq 0.05$ ), **highly statistically significant (if $\mathrm{P}<0.001$ ).

Table (4): Association between demographic data, obstetric history, serum vitamin D level and urinary specific gravity-corrected bisphenol A among the studied preterm cases.

\begin{tabular}{llc}
\hline Variables & SG-Corrected BPA & Test of \\
& Median (min-max) & $\begin{array}{c}\text { significance } \\
\text { (P value) }\end{array}$
\end{tabular}

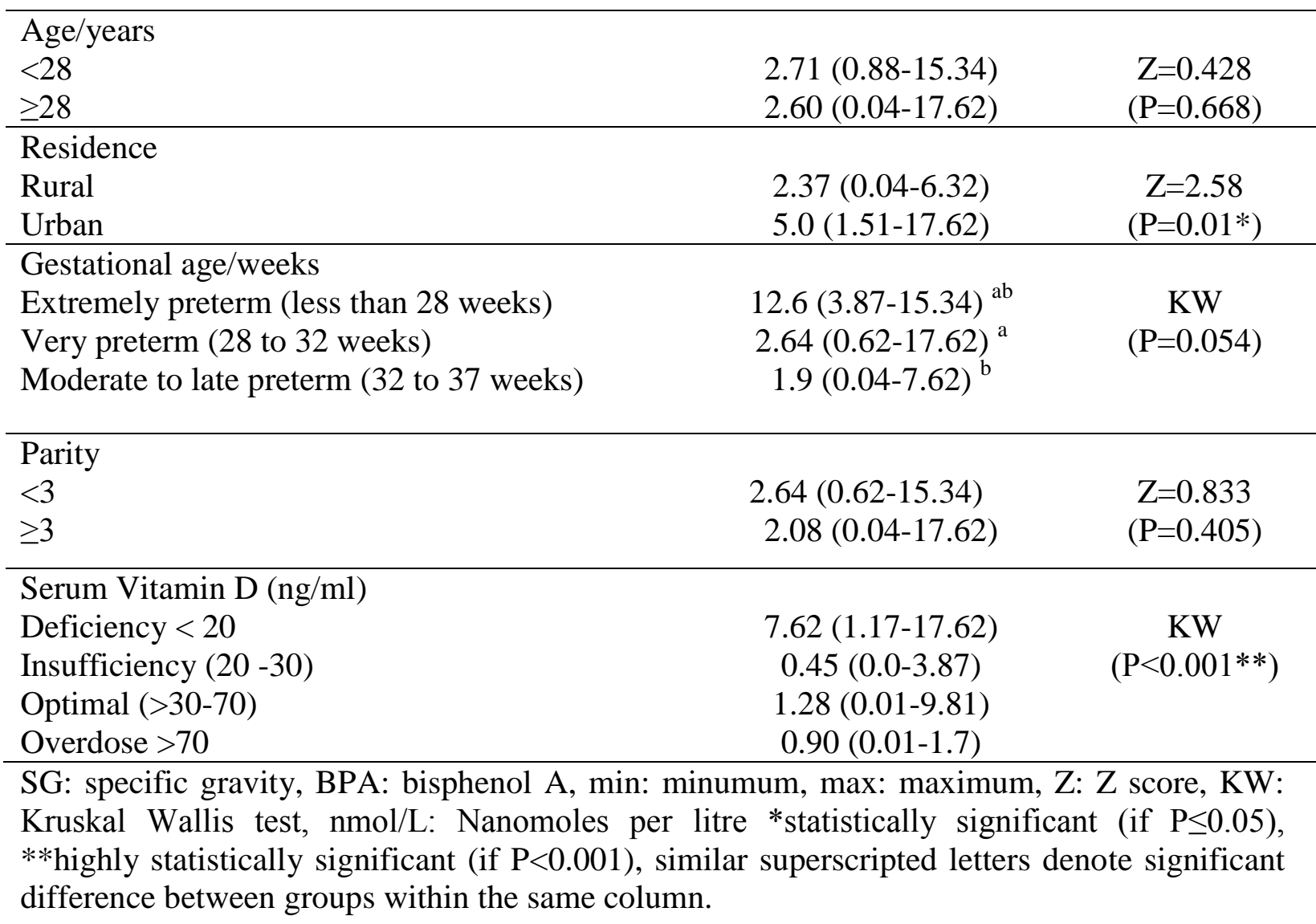


Table (5): The correlation between serum vitamin $D$ and both urinary uncorrected and Specific Gravity-corrected Bisphenol A among the studied preterm group.

\section{Serum vitamin D}

Uncorrected BPA

$\begin{array}{ll}\mathrm{r} & -0.644^{* *} \\ \mathrm{p} & <0.001^{* *}\end{array}$

SG-Corrected BPA

$$
-0.638^{* *}
$$$$
<0.001 * *
$$

BPA: Bisphenol A, SG: specific gravity, r: Spearman correlation coefficient *statistically significant (if $\mathrm{P} \leq 0.05$ ), **highly statistically significant (if $\mathrm{P}<0.001$ ).

Table (6): Predictors of preterm labor among the studied groups:

\begin{tabular}{|c|c|c|c|c|}
\hline \multirow[t]{2}{*}{ Variables } & \multirow{2}{*}{$\begin{array}{c}\text { Standardized } \\
\text { coefficient } \\
\beta\end{array}$} & \multirow[t]{2}{*}{$\mathrm{P}$ value } & \multirow[t]{2}{*}{ Odds ratio } & $(95 \% \mathrm{CI})$ \\
\hline & & & & $\begin{array}{cc}\text { Lower } & \text { Upper } \\
\text { limit } & \text { limit }\end{array}$ \\
\hline Age of the female & 0.019 & 0.579 & 1.02 & $0.953-1.09$ \\
\hline Parity & -0.034 & 0.899 & 0.966 & $0.569-1.64$ \\
\hline $\begin{array}{l}\text { Urinary uncorrected } \\
\text { BPA }\end{array}$ & 1.052 & $<0.001 * *$ & 2.86 & $1.76-4.66$ \\
\hline $\begin{array}{l}\text { Urinary SG-Corrected } \\
\text { BPA }\end{array}$ & 1.13 & $<0.001 * *$ & 3.09 & $1.81-5.31$ \\
\hline Serum vitamin D & 0.002 & 0.879 & 1.002 & $0.981-1.02$ \\
\hline
\end{tabular}

BPA: Bisphenol A, SG: specific gravity, CI: confidence interval, *statistically significant (if $\mathrm{P} \leq 0.05$ ), **highly statistically significant (if $\mathrm{P}<0.001$ ).

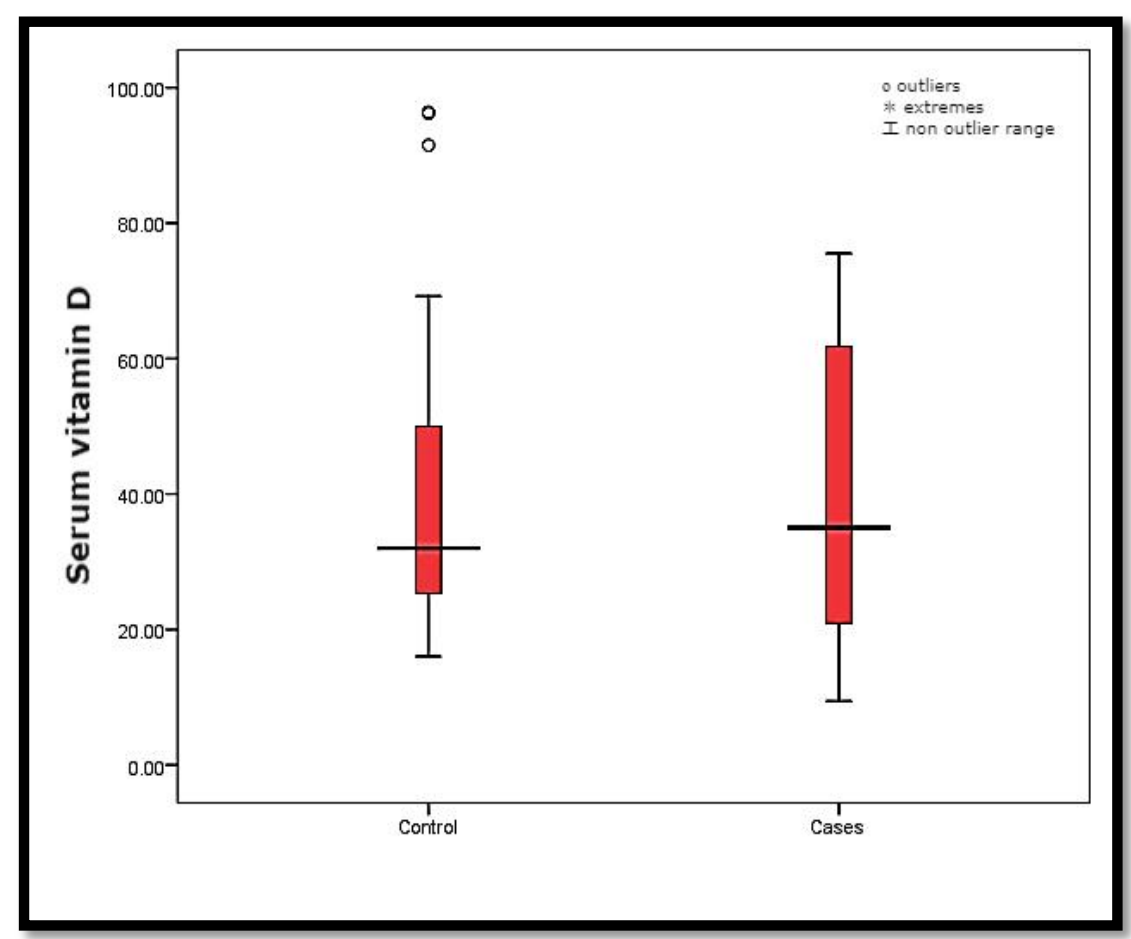

Figure (1): Box \& Whisker plot showing the median serum vitamin D levels (ng/ml) of the studied groups. 


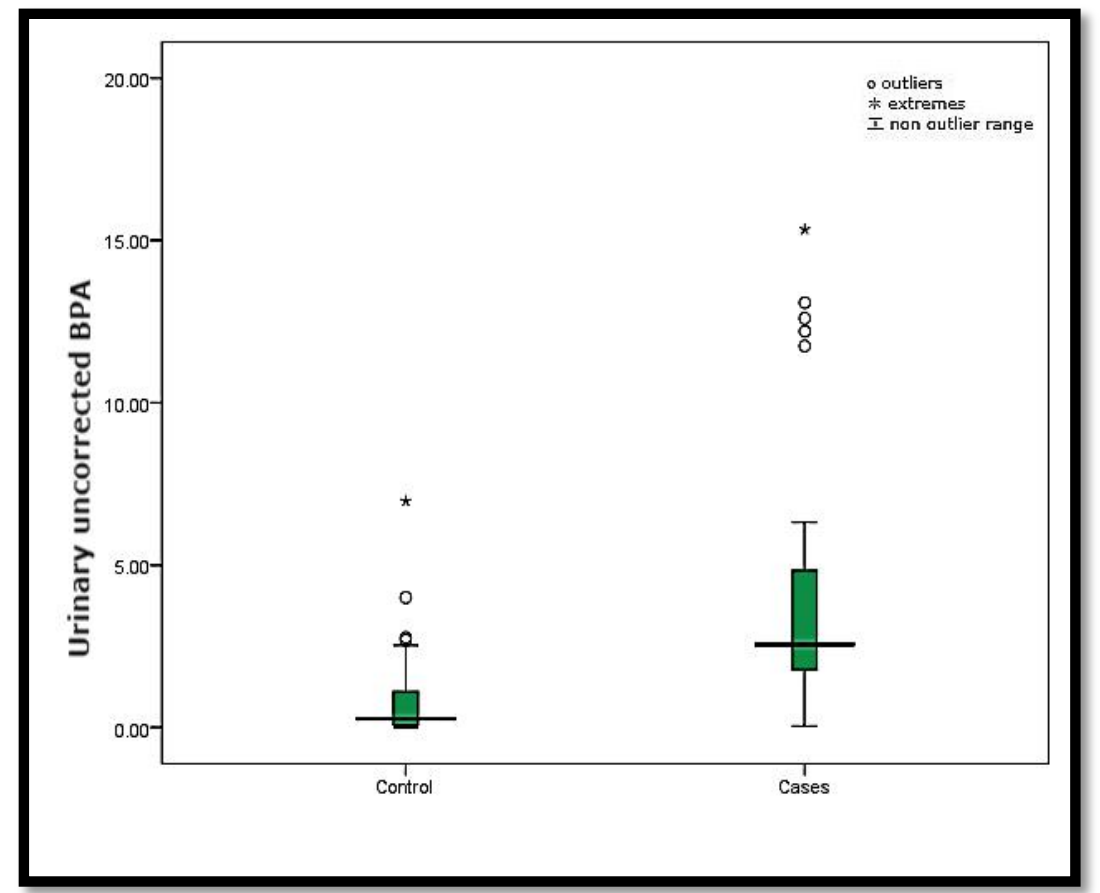

Figure (2): Box \& Whisker plot showing the median urinary uncorrected bisphenol A levels $(\mathrm{ng} / \mathrm{ml})$ of the studied groups.

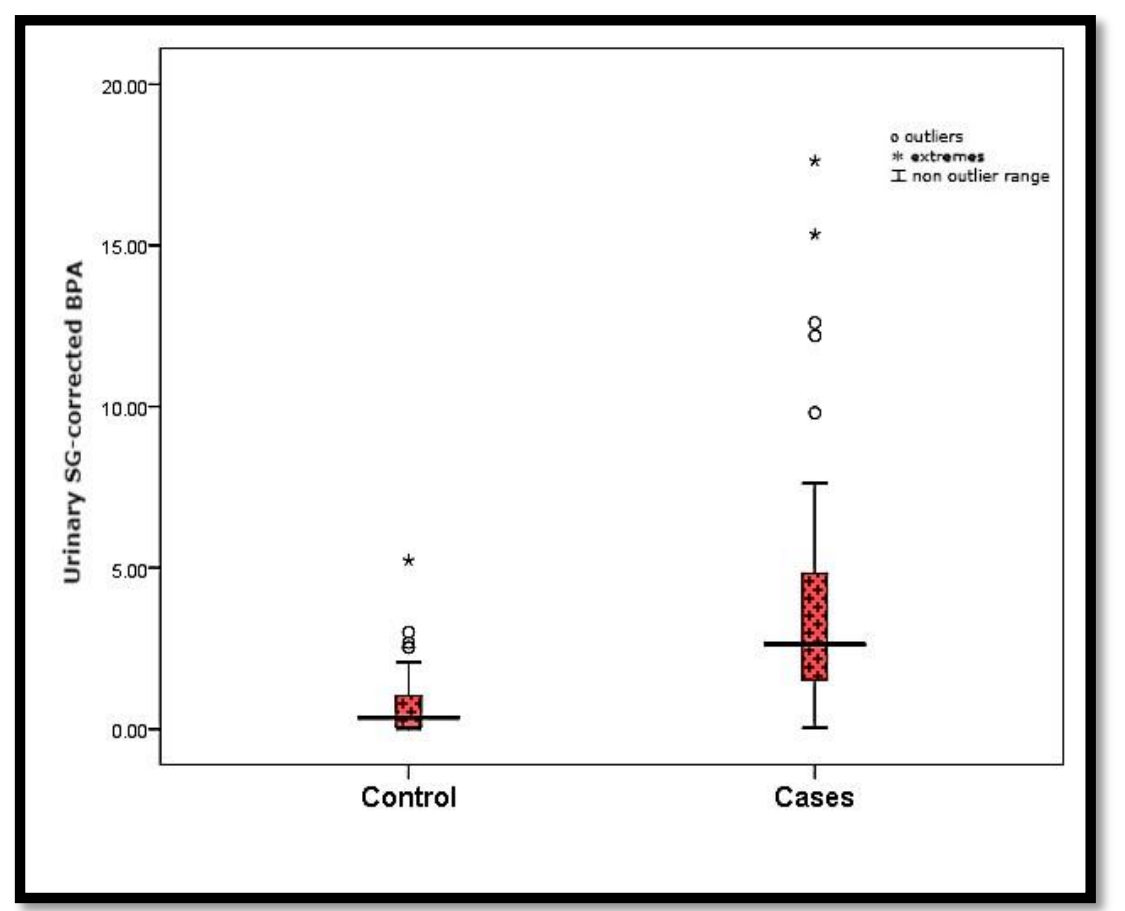

Figure (3): Box \& Whisker plot showing the median urinary specific gravity-corrected bisphenol A levels (ng/ml) of the studied groups. 


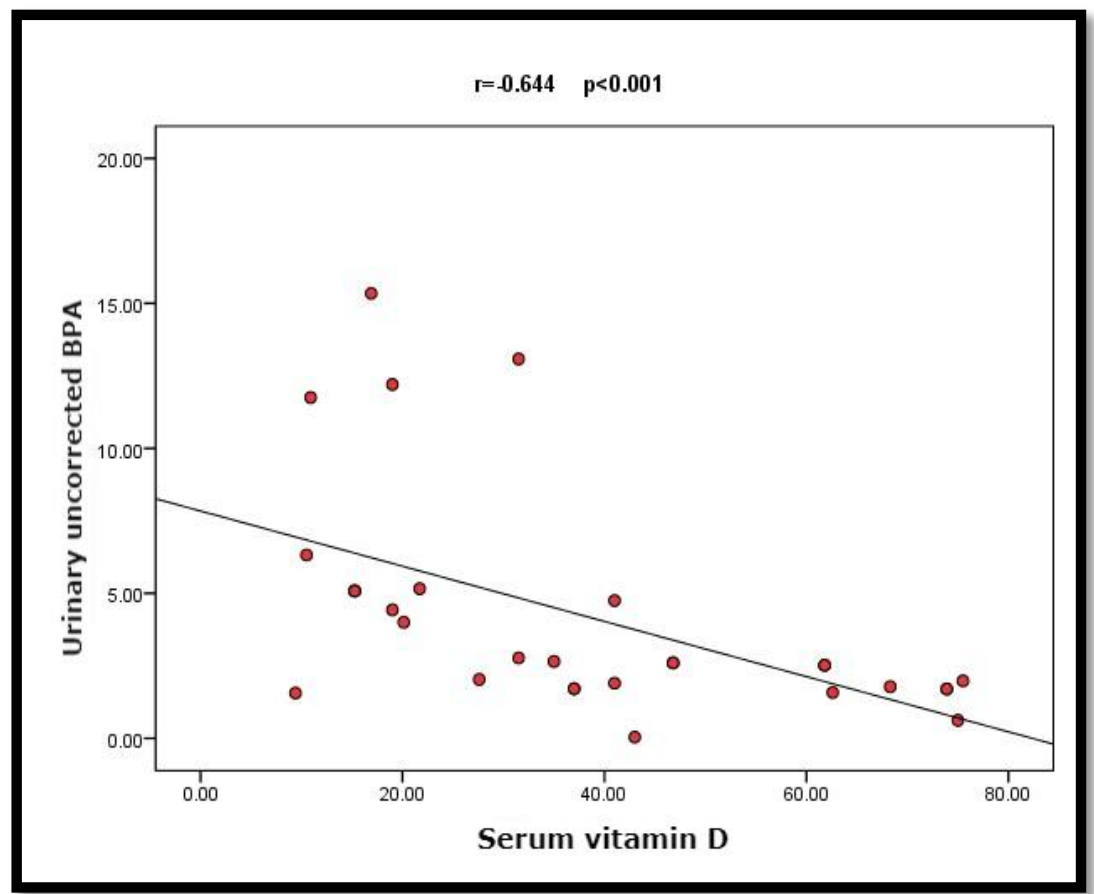

Figure (4): Scatter diagram showing the correlation between serum Vitamin D (ng/ml) and urinary uncorrected bisphenol A levels (ng/ml) of the studied PTB group.

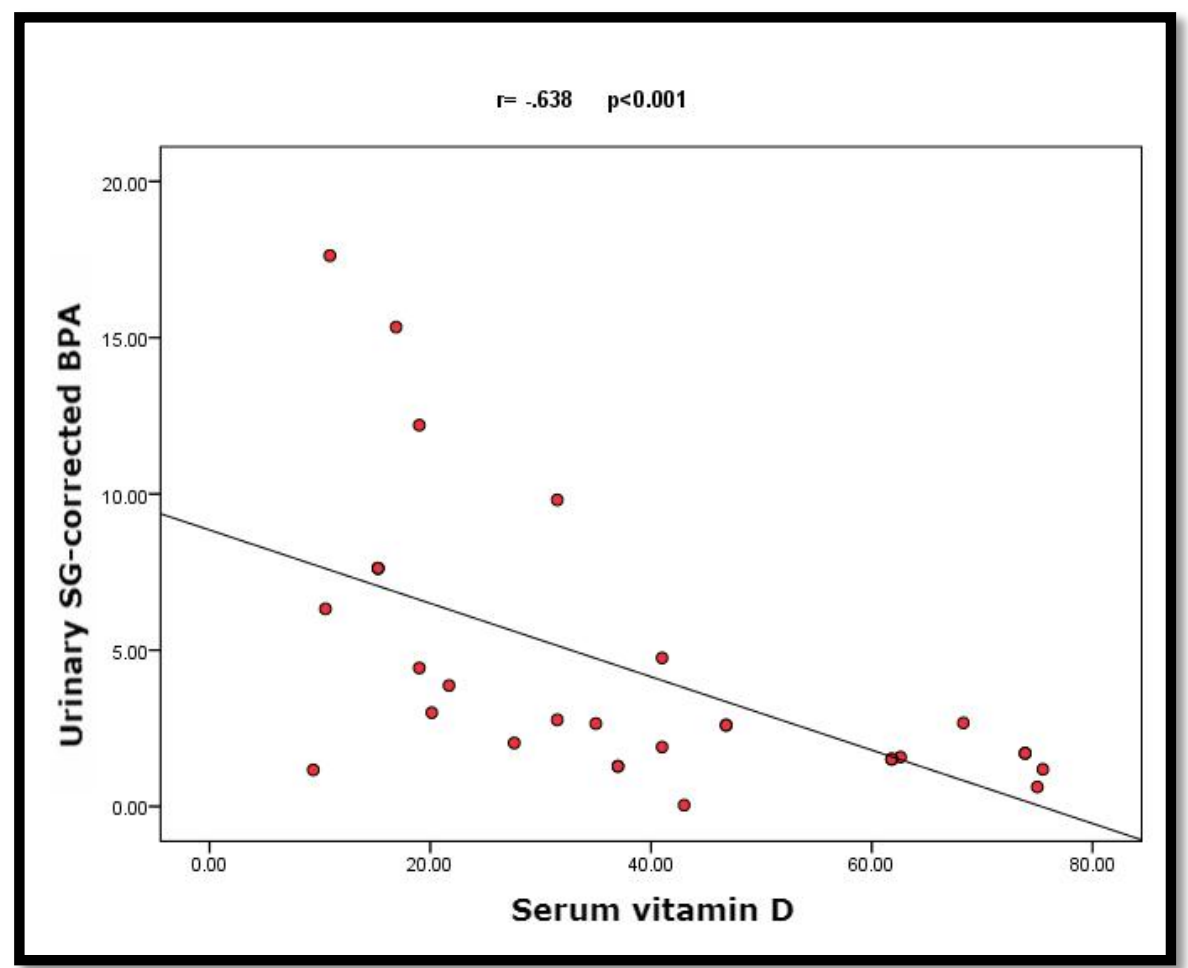

Figure (5): Scatter diagram showing the correlation between serum Vitamin D (ng/ml) and urinary specific gravity-corrected bisphenol A levels $(\mathrm{ng} / \mathrm{ml})$ of the studied PTB group. 


\section{DISCUSSION}

Bisphenol A is considered a classic EDC that at low doses, disrupts hormonal homeostasis and act as reproductive and an ovarian toxicant (Peretz et al., 2014). Prenatal exposure to EDCs especially phenolic EDCs is considered a potential risk factor for PTBs. Unfortunately, human exposure to BPA is inevitable (Porpora et al., 2019).

Regarding sociodemographic data of the studied groups, the mean age of both control and PTB groups was 28.26 \pm 6.39 and $29.11 \pm 6.78$ years. This was nearly similar to the study conducted by Klemetti et al. (2016) on a Finland governmental cohort study in which the threshold-age for PTB was around 28 years.

As regards obstetric history, the mean gestational age per weeks at the time of delivery of both control and PTB groups was $38.0 \pm 1.02$ and $31.75 \pm 2.43$ weeks respectively with high statistically significant difference between both groups. About $43.4 \%$ and $43.5 \%$ of control and PTB groups respectively were para 1 . Similarly, a study by Khalil et al. (2020) on a total of 84 cases, the median gestational age of PTB was 31.3 weeks.

Low gynecological age is a PTB risk factor as young mothers are still growing during their pregnancy, which ends with nutritional competition in between the mother and the fetus (Demirci et al., 2016).

Regarding the median level of urinary uncorrected and SG-corrected BPA, it was found to be higher in PTB group (2.56, $2.63 \mathrm{ng} / \mathrm{ml}$ respectively) versus control group $(0.26,0.35 \mathrm{ng} / \mathrm{ml}$ respectively) with high statistically significant difference between both studied groups $(\mathrm{p}<0.001)$.

Because of its widespread use, urinary BPA concentrations have been found in a variety of populations, including pregnant women's serum, follicular fluid, placental tissue, and cord blood (Philippat et al., 2014).
Similarly, in Mexico City 2010, a case control study of PTB found that the median level of urinary uncorrected and SG-corrected BPA concentration was higher $(2.5,1.94 \mathrm{ng} / \mathrm{ml}$ respectively) in PTB women compared to women with full term delivery (Cantonwine et al., 2010).

Spontaneous preterm labor could be precipitated by BPA exposure due to variety of hormone-mediated mechanisms and an inappropriate intrauterine inflammatory cascade (Ferguson and Chin, 2017).

The studied groups were evaluated for vitamin D deficiency and insufficiency. It was found that vitamin $\mathrm{D}$ deficiency presented in $1.9 \%$ of cases in the control group and $35.8 \%$ of cases in the PTB group. On the other hand, vitamin D insufficiency was in $30.2 \%$ of cases in the control group and $17 \%$ of cases in the PTB group with statistically significant difference $(\mathrm{P}=0.001)$ between both the studied groups. The median serum vitamin D level was found to be $32(16-96.4) \mathrm{ng} / \mathrm{ml}$ in the control group while in the PTB group was $35(9.4-75.5) \mathrm{ng} / \mathrm{ml}$ with no statistically significant difference $(\mathrm{P}=0.945)$ among the studied groups.

In accordance with these results, Botros et al. (2015) reported a prevalent severe vitamin D deficiency among Egyptian females. Despite the fact that $55 \%$ of mothers were supplemented with vitamin $\mathrm{D}$, maternal vitamin $\mathrm{D}$ levels were insufficient/deficient in $40 \%$ of mothers in the Panda et al. (2019) cohort study.

These findings are consistent with those of Habibesadat et al. (2014) and Joshi and Bhatia (2014), who found that despite the tropical environment, vitamin D deficiency and insufficiency are common among females, likely due to insufficient sun exposure related to cultural/social factors and avoiding sun exposure for cosmetic reasons, as well as insufficient dietary calcium.

Vitamin D protective role against PTB is established by anti-inflammatory cytokines generation and activation of 
monocytes and macrophages in response to any microbial invasion. Moreover, it also improves placental function and reduces oxidative free radicals damage which is associated with preeclampsia and PTB (Cyprian et al., 2019).

However, some observational studies did not show a significant relationship between vitamin D deficiency and PTB risk (Choi et al., 2016, Ong et al., 2016 and AL shaikh et al., 2016). Many confounding factors of each study could be responsible for this inconsistency for example residence, ethnicity, time of sampling during pregnancy and analytical method assay and adjustment used.

Regarding association between demographic data, obstetric history, serum vitamin D level and urinary SG-corrected BPA among the studied PTB cases, there was no statistically significant association between high urinary SG-corrected BPA levels and the age of the pregnant female $(\mathrm{P}=0.668)$ nor her parity status $(\mathrm{P}=0.405)$. Moreover, there was no statistically significant association between high urinary SG-corrected BPA levels and the median gestational age and preterm degree of the pregnant female $(\mathrm{P}=0.054)$.

Among a study in New York, Wolff et al. (2008) found that urinary adjusted BPA concentration mainly during the third trimester was not significantly associated with the gestational length. In different circumstances, an increase in urinary BPA concentrations among 72 women living in New Jersey was associated with a decrease in gestational length during pregnancy exposure.

Differences in study size and nature, differences in populations and usage of different biological media for exposure assessment could explain the contradictory evidence between BPA exposure and either risk of PTB or gestational length (Cantonwine et al., 2015).

In the present study, there was a statistically significant association of high urinary SG-corrected BPA levels in cases who lived in urban areas $(\mathrm{P}=0.01)$. In Okinawa, Japan, kitada et al. (2008) found lower BPA levels in rural areas relative to urban areas, implying higher BPA emission from industrial wastes and less so from agricultural activities, in addition to Fu et al. (2010) who found higher atmospheric BPA concentrations in urban Indian regions where open-air burning of plastic waste is common.

On the other hand, there was a statistically significant association between high urinary SG-corrected BPA levels and serum vitamin $\mathrm{D}$ deficiency $(\mathrm{P}=0.003)$. Moreover, the correlation coefficients between uncorrected, SG-corrected BPA and vitamin $\mathrm{D}$ among PTB group were $(\mathrm{r}=-$ $0.644)$ and $(r=0.638)$ respectively with statistically significant strong negative correlation $(\mathrm{P}<.001)$.

There are few studies inspecting the association and correlation between urinary BPA and serum vitamin D levels among PTB group. Johns et al. (2017) reported inverse relationships between phenol metabolites and total 25(OH)D level in the overall population analysis and these associations were strongest in women. These findings were consistent with those reported by Erden and colleagues (2014), who found a suggestive inverse correlation between serum BPA and $25(\mathrm{OH}) \mathrm{D}$ levels in 128 participants.

The inverse relationships reported in the current work between BPA and vitamin $\mathrm{D}$ levels may be explained by various potential direct or indirect mechanisms acting on vitamin $\mathrm{D}$ endocrine system. Furthermore, the activity of cytochrome P450 enzymes that are involved in the vitamin $D$ active metabolites production can be induced or inhibited by BPA thus inflecting levels of circulating 25(OH)D (Pivonello et al., 2020).

There are several limitations of this study, due to the limited sample size and single-center research, a thorough risk analysis of the factors affecting exposure in this population may be difficult. Since 
urinary BPA concentrations have been shown to be highly variable throughout pregnancy (Shen et al., 2020), it would have been better to obtain several samples during the pregnancy, but this was not applicable due to financial constraints.

However, this is one of the few Egyptian studies to evaluate the value of urinary BPA and serum vitamin D levels in predicting PTB after excluding a wide range of PTB etiologies using new, highly sensitive analytical methods to quantify urinary analytes.

\section{CONCLUSIONS}

Urinary BPA levels represent a possible predictive environmental risk factor for PTB. Furthermore, vitamin D deficiency is a global problem among pregnant women. Finally, these findings conclude an association between BPA exposure and PTB which necessitate further affirmatory studies.

\section{RECOMMENDATIONS}

According to the present study, the following guidelines are recommended: (1) Health programs should be conducted for data collection and providing information to the public about sources of exposure to BPA and its toxic effects on human health. (2) Biological monitoring by periodic measurement of urinary BPA and serum vitamin $\mathrm{D}$ during pregnancy that should be performed on a regular basis to evaluate the effectiveness of primary prevention and to assist clinicians in assessing the grade of exposure. (3) Bisphenol A exposure should be eliminated as far as possible by banning all non-essential uses of it such as plastics and canned food. (4) Vitamin D supplementation may be regarded as a method of primary prevention in terms of improving vitamin D status in adolescent girls and women of reproductive age in order to reduce maternal and perinatal morbidity.

\section{Acknowledgements:}

The authors wish to convey to laboratory technicians at Mansoura Research Center for Cord Stem Cell, Faculty of Medicine" their full appreciation.

\section{Conflict of interest:}

All authors confirm that there are no declarations of interest.

\section{REFERENCES}

1. Al-Shaikh GK, Ibrahim GH, Fayed AA, Al-Mandeel H (2016): Impact of vitamin $D$ deficiency on maternal and birth outcomes in the Saudi population: a crosssectional study. BMC pregnancy and childbirth, 16:119.

2. Baer RJ, Berghella V, Muglia LJ, Norton ME, Rand L, Ryckman KK, Jelliffe-Pawlowski LL, McLemore MR (2019): Previous Adverse Outcome of Term Pregnancy and Risk of Preterm Birth in Subsequent Pregnancy. Matern Child Health J; 23(4):443-450.

3. Botros RM, Sabry IM, Abdelbaky RS, Eid YM, Nasr MS, Hendawy LM (2015): Vitamin D deficiency among healthy Egyptian females. Endocrinol; 62(7):314321.

4. Cantonwine D, Meeker JD, Hu H, Sánchez BN, Lamadrid-Figueroa H, Mercado-García A, Fortenberry GZ, Calafat AM, Téllez-Rojo MM (2010): Bisphenol a exposure in Mexico City and risk of prematurity: a pilot nested case control study. Environ Health; 9:62 .

5. Cantonwine DE, Ferguson KK, Mukherjee B, McElrath TF, Meeker JD (2015): Urinary bisphenol A levels during pregnancy and risk of preterm birth. Environ Health Perspect; 123(9):895-901.

6. Chang SW, Lee HC (2019): Vitamin D and health-The missing vitamin in humans. Pediatr Neonatol; 60(3):237-244.

7. Choi BI, Harvey AJ, Green MP (2016). Bisphenol A affects early bovine embryo development and metabolism that is negated by an oestrogen receptor inhibitor. Scientific reports; 6:29318.

8. Cyprian F, Lefkou E, Varoudi K, Girardi G (2019): Immunomodulatory Effects of Vitamin D in Pregnancy and Beyond. Fronts immunol; 10: 2739.

9. Demirci O, Yılmaz E, Tosun Ö, Kumru P, Arınkan A, Mahmutoğlu D, Selçuk S, Dolgun $Z$ N, Arisoy R, Erdoğdu E, Tarhan N (2016): Effect of Young 
Maternal Age on Obstetric and Perinatal Outcomes: Results from the Tertiary Center in Turkey. Balkan med J;33(3): 344-349.

10. Erden ES, Genc S, Motor S, Ustun I, Ulutas KT, Bilgic HK, Oktar S, Sungur S, Erem C, Gokce C (2014): Investigation of serum bisphenol A, vitamin $\mathrm{D}$, and parathyroid hormone levels in patients with obstructive sleep apnea syndrome. Endocrine; 45(2):311-318.

11. Ferguson KK, Chin HB (2017): Environmental chemicals and preterm birth: Biological mechanisms and the state of the science. Curr Epidemiol Rep; 4(1): 56-71.

12. Fu P, Kawamura K (2010): Ubiquity of bisphenol A in the atmosphere. Environ Pollut; 158(10):3138-3143 .

13. Habibesadat $S$, Ali $K$, Shabnam J, Arash A (2014): Prevalence of vitamin D deficiency and its related factors in children and adolescents living in North Khorasan, Iran. $J$ Pediatr Endocrinol Metab; 27 (6):431-436 .

14. Johns LE, Ferguson KK, Cantonwine DE, McElrath TF, Mukherjee B, Meeker JD (2017): Urinary BPA and Phthalate Metabolite Concentrations and Plasma Vitamin D Levels in Pregnant Women: A Repeated Measures Analysis. Environ Health Perspect; 125(8): 087026 .

15. Johnson SA, Javurek AB, Painter MS, Ellersieck MR, Welsh TH Jr, Camacho L, Lewis SM, Vanlandingham MM, Ferguson SA, Rosenfeld CS (2016): Effects of developmental exposure to bisphenol $A$ on spatial navigational learning and memory in rats: $\mathrm{A}$ CLARITY-BPA study. Horm Behav; 80:139-148.

16. Joshi K, Bhatia V (2014): Vitamin D deficiency in a tropical country-treatment and prevention in children. Indian $J$ Pediatr.; 81:84-89.

17. Khalil A, von Dadelszen P, Draycott $T$, Ugwumadu A, O'Brien $P$, Magee $L$ (2020): Change in the Incidence of Stillbirth and Preterm Delivery During the
COVID-19 Pandemic. JAMA; 324(7):705706 .

18. Kitada Y, Kawahata H, Suzuki A, Oomori $T$ (2008): Distribution of pesticides and bisphenol $\mathrm{A}$ in sediments collected from rivers adjacent to coral reefs. Chemosphere; 71: 2082-2090 .

19. Klemetti $R$, Gissler $M$, Sainio $S$, Hemminki E (2016): At what age does the risk for adverse maternal and infant outcomes increase? Nationwide registerbased study on first births in Finland in 2005-2014. Acta Obstet Gynecol Scand; 95:1368-1137.

20. Liao $C$ and Kannan K. (2012): Determination of free and conjugated forms of bisphenol $\mathrm{A}$ in human urine and serum by liquid chromatography-tandem mass spectrometry. Environ Sci Technol; 46(9):5003-5009 .

21. Murthi P, Yong HE, Ngyuen TP, Ellery S, Singh H, Rahman R, Dickinson H, Walker DW, Davies-Tuck M, Wallace EM, Ebeling PR (2016): Role of the Placental Vitamin D Receptor in Modulating Feto-Placental Growth in Fetal Growth Restriction and PreeclampsiaAffected Pregnancies. Front Physiol; 18(7):43.

22. Mustieles V, Williams PL, Fernandez MF, Mínguez-Alarcón L, Ford JB, Calafat AM, Hauser R, Messerlian C. (2018): Environment and Reproductive Health (EARTH) Study Team. Maternal and paternal preconception exposure to bisphenols and size at birth. Hum Reprod; 33(8):1528-1537 .

23. Ong YL, Quah PL, Tint MT Aris IM, Chen LW, van Dam RM, Heppe D, Saw SM, Godfrey KM, Gluckman PD, Chong YS, Yap F, Lee YS, Foong-Fong Chong $M$ (2016): The association of maternal vitamin D status with infant birth outcomes, postnatal growth and adiposity in the first 2 years of life in multi- ethnic Asian population: The Growing Up in Singapore Towards healthy Outcomes (GUSTO) cohort study. Br J Nutr; 116: 621-631. 
24. Panda M, McIntosh J, Chaudhari T, Kent AL (2019): "Do Maternal Vitamin D Levels Influence Vitamin D Levels in Preterm Neonates?", Int J Pediatr; 1-7.

25. Philippat C, Botton J, Calafat AM, Ye X, Charles MA, Slama R (2014): Prenatal exposure to phenols and growth in boys. Epidemiol.; 25:625-635 .

26. Pivonello C, Muscogiuri G, Nardone A, Garifalos F, Provvisiero DP, Verde N, de Angelis C, Conforti A, Piscopo M, Auriemma RS, Colao A, Pivonello R (2020): Bisphenol A: an emerging threat to female fertility. Reprod Biol Endocrinol; 18:22.

27. Porpora MG, Piacenti I, Scaramuzzino S, Masciullo L, Rech F, Benedetti Panici $P$ (2019): Environmental Contaminants Exposure and Preterm Birth: A Syst Rev Toxics; 7(1): 11.

28. Shen J, Kang Q, Mao Y, Yuan M, Le F, Yang $X$, Jin F (2020): Urinary bisphenol A concentration is correlated with poorer oocyte retrieval and embryo implantation outcomes in patients with tubal factor infertility undergoing in vitro fertilisation. Ecotoxicol Environ Saf; 187: 109816.
29. Tehrani F.R, Behboudi-Gandevani S. (2017): Vitamin D and Human Reproduction. In: A Critical Evaluation of Vitamin D - Basic Overview. 1st ed. IntechOpen, Tahran, Iran, pp. 247-295.

30. Weinberger B, Vetrano AM, Archer FE, Marcella SW, Buckley B, Wartenberg D, Robson MG, Klim J, Azhar S, Cavin S, Wang L, Rich DQ (2014): Effects of maternal exposure to phthalates and bisphenol A during pregnancy on gestational age. J Matern Fetal Neonatal Med; 27(4):323-327.

31. Wolff MS, Engel SM, Berkowitz GS, Ye X, Silva MJ, Zhu C, Wetmur J, Calafat AM (2008): Prenatal phenol and phthalate exposures and birth outcomes. Environ Health Perspect; 116:1092-1097. 